\title{
Associations between Peritoneal Daily Phosphate Removal and Regulators of Phosphate Metabolism Including Fibroblast Growth Factor 23 in Peritoneal Dialysis Patients
}

\author{
Margarida Sarmento-Dias ${ }^{1,2,3}$, Carla Santos-Araújo ${ }^{4,5}$, Rui Poínhos ${ }^{3}$, Bruno Oliveira $^{3}$, Maria João Sousa ${ }^{4}$, Liliana Simões Silva ${ }^{1,2}$, Isabel
} Soares Silva ${ }^{1,2}$, Flora Correia ${ }^{1,2,3}$ and Manuel Pestana ${ }^{1,2,4,6}$

${ }^{1}$ Institute for Innovation ans Health Research (I3S), Portugal

2Institute of Biomedical Engineering (INEB), Portugal

${ }^{3}$ Faculty of Nutrition and Food Science, University of Porto, Portugal

${ }^{4}$ Nephrology Department, São João Hospital Center, Portugal

${ }^{5}$ Cardiovascular Research and Development Unit, Portugal

${ }^{6}$ Department of Renal, Urologic and Infectious Diseases, Faculty of Medicine, University of Porto, Portugal

\begin{abstract}
Aim: Increased FGF23 blood levels were found intact and biologically active in peritoneal dialysis (PD) patients. We aimed to evaluate in PD patients the associations between regulators of phosphate $(\mathrm{Pi})$ metabolism including FGF23 and peritoneal daily Pi removal (PDPiR).

Methods: Sixty-four adult patients (male $56 \%$, mean age $48 \pm 13$ years, median time on PD 3.4 months) were evaluated in a cross-sectional study (ST1). Daily Pi intake was assessed by food frequency questionnaire. Intact FGF23 blood levels were evaluated by ELISA (Immutopics, Inc., San Clemente, CA). The first 33 patients who completed 1 year after the first evaluation were re-evaluated. (longitudinal study, ST2).

Results: In ST1, both circulating FGF23 and Pi serum levels were associated with PDPiR $(\beta=0.533, p=0.002$ and $\beta=0.342, p=0.045$, respectively) independent of $i P T H$, dietary $P i$ intake, renal daily $P i$ removal, dialysate/plasma creatinine concentration ratio (D/P Cr), residual renal function (RRF), ultrafiltration volume, dwell volume, number of exchanges and dialysis vintage. In ST2, the increase in PDPiR was only correlated with the increase in FGF23 $(\beta=0.480$, $\mathrm{p}=0.012$ ) independently of changes in serum $\mathrm{Pi}, \mathrm{RRF}$, renal daily $\mathrm{Pi}$ removal and $\mathrm{D} / \mathrm{P} \mathrm{Cr}$.
\end{abstract}

Conclusions: Differences in circulating FGF23 and Pi serum levels contribute both independently to heterogeneity of PDPiR in PD patients

Keywords: Fibroblast growth factor 23; Peritoneal dialysis; Peritoneal daily phosphate removal; Serum phosphate

\section{Introduction}

Elevated serum phosphate $(\mathrm{Pi})$ concentrations contribute to the development of arterial calcification, myocardial hypertrophy and endothelial dysfunction [1-3] and numerous observational studies have shown a significant and independent association between elevated serum $\mathrm{Pi}$ levels and cardiovascular mortality in patients with chronic kidney disease (CKD) [4-7]. Recently, fibroblast growth factor-23 (FGF23) was described as an endocrine hormone produced by osteocytes that directly regulates $\mathrm{Pi}$ homeostasis [8-10]. The expression of FGF23 is up regulated by increased serum Pi levels and directly reduces tubular Pi reabsorption by decreasing the expression of sodium-dependent Pi transporters in renal proximal tubules [11-14]. In pre-dialysis CKD patients, FGF23 blood levels are elevated earlier than either Pi or parathormone (iPTH) thus suggesting that FGF23 might be a sensitive early biomarker of disordered Pi metabolism that helps maintain normal serum Pi levels despite reduced renal function $[15,16]$. Although the exact CKD stage when FGF23 levels first become significantly elevated differs across studies, higher FGF23 on a continuous scale was consistently associated with higher serum $\mathrm{Pi}$ levels, higher fractional excretion of $\mathrm{Pi}$, lower estimated glomerular filtration rate (eGFR) and lower levels of 1,25-dihydroxyvitamin D [1720]. Circulating FGF23 in PD patients was found to be mostly intact and biologically active [21]. However, the specific effects of FGF23 on Pi balance are less clear in this population. Recent studies consistently provided evidence for a strong positive association between serum $\mathrm{Pi}$ and circulating FGF23 in both incident and prevalent PD patients
[22-24]. In addition, Isakova et al. reported in adult PD patients that among those with residual renal function (RRF) there is a continuous relationship between higher FGF23 and lower RRF and that longer dialysis vintage also independently associates with higher FGF23 [24]. It remains unclear, however, whether elevated FGF23 levels are associated with peritoneal Pi elimination. In studies that examined associations between FGF23 serum levels and peritoneal Pi clearance there was no significant relationship in patients with or without RRF $[22,24]$. However, we must bear in mind that peritoneal Pi clearance is calculated by the ratio of peritoneal daily Pi removal (PDPiR) and serum Pi levels and the latter are well recognized to be associated independently with FGF23. Moreover, although it has been suggested that PDPiR is indicative merely of Pi intake in the steady state [25] the association between PDPiR and regulators of Pi homeostasis such as FGF23, Pi serum levels, iPTH and dietary Pi intake was not

*Corresponding author: Pestana M, Alameda Prof. Hernani Monteiro, Porto, Portugal, E-mail: mvasconcelos@hsjoao.min-saude.pt

Received: October 10, 2015; Accepted: December 29, 2015; Published: December 31, 2015

Citation: Sarmento-Dias M, Santos-Araújo C, Poínhos R, Oliveira B, Sousa M et al. (2015) Associations between Peritoneal Daily Phosphate Removal and Regulators of Phosphate Metabolism Including Fibroblast Growth Factor 23 in Peritoneal Dialysis Patients. J Kidney 1: 109. doi:10.4172/2472-1220.1000109

Copyright: () 2015 Sarmento-Dias M, et al. This is an open-access article distributed under the terms of the Creative Commons Attribution License, which permits unrestricted use, distribution, and reproduction in any medium, provided the original author and source are credited. 
Citation: Sarmento-Dias M, Santos-Araújo C, Poínhos R, Oliveira B, Sousa M, et al. (2015) Associations between Peritoneal Daily Phosphate Removal and Regulators of Phosphate Metabolism Including Fibroblast Growth Factor 23 in Peritoneal Dialysis Patients. J Kidney 1: 109. doi:10.4172/2472-1220.1000109

examined so far. In the present study we aimed to evaluate in stable adult PD patients the associations between PDPiR and regulators of Pi metabolism including FGF23. We also examined in a longitudinal study the time-dependent changes in RRF and their association with FGF23 serum levels and PDPiR.

\section{Materials and Methods}

\section{Study population}

Patients aged 18 years or older who had been undergoing chronic PD for the treatment of ESRD for at least 45 days at São João Hospital Centre were invited to participate in the study. Patients with a recent history (less than 3 months) of infection or acute cardiovascular episode were excluded. The medical records for each subject such as underlying kidney disease, duration of PD, cardiovascular disease history and other illnesses were abstracted. The study protocol was developed in adherence to the Declaration of Helsinki and was approved by the Ethics Committee for Health and Institutional Review Board of São João Hospital Centre. All patients provided written informed consent prior to the inclusion in the study.

\section{Procedures}

Sixty-four patients were included in a cross-sectional study. Patients were asked to attend to our Unit in two consecutive days. On day 1 they were instructed to bring 24-hour dialysate and urine collections and fasting plasma samples were obtained; on day 2 a combined peritoneal equilibration test (PET) was performed [26]. In particular, a combination of bicarbonate/lactate $(25 / 15 \mathrm{mmol} / \mathrm{L})$ was used as buffer, with a nominal pH of 7.4 and a sodium concentration of 132 $\mathrm{mmol} / \mathrm{L}$. Dietary Pi intake was assessed in a subset of 51 patients using a semiquantitative food

frequency questionnaire (FFQ), validated for the Portuguese adult population [27]. The FFQ is an 86-item questionnaire that assesses usual dietary intake over the previous 12 months, including food groups and beverages. Food intake was calculated by weighting one of the nine possibilities of frequency of consumption (from never or less than once per month, to six or more times a day), by the weight of the standard portion size of the food-item in grams. In addition, the same subset of 51 patients completed a food record to estimate average daily dietary intake of $\mathrm{Pi}$, on the 2-day period before blood and dialysate collections. The conversion of food intake into nutrients was conducted based on the software Food Processor Plus (ESHA Research, Salem, Oregon), with nutritional information from food composition tables of United States Department of Agriculture, adapted to foods typically Portuguese [28]. Similar clinical and laboratory assessments were performed in a subset of 33 patients evaluated longitudinally, 12 months after the first evaluation. Patients enrolled in the longitudinal study were the first to complete a year after the first evaluation.

\section{Assays}

Routine laboratory testing of blood, dialysate, and urinary samples was performed by local laboratory using standard procedures. Dialysate and urinary $\mathrm{Pi}$ concentrations were measured using standard autoanalysers. All patients used commercially available PD solutions. The dialysate creatinine concentration was corrected for interference by glucose according to laboratory standards (correction factor $=0.0001887$ ). In the 64 patients included in cross-sectional study serum FGF23 levels were measured using Human Intact FGF23 ELISA kits (Immutopics, San Clemente, CA, USA), in duplicate. Blood was collected in BD Vacutainer tubes (Becton Dickinson, Madrid,
Spain) containing aprotinin to prevent proteolysis and K3EDTA as anticoagulant. The reported assay parameters were sensitivity $1.0 \mathrm{pg} /$ $\mathrm{mL}$, intra-assay coefficient of variation $4.4 \%$ at $14.6 \mathrm{pg} / \mathrm{mL}$ and $2.6 \%$ at $148 \mathrm{pg} / \mathrm{mL}$, and inter-assay coefficient of variation, $6.1 \%$ at $15.6 \mathrm{pg} / \mathrm{mL}$ and $6.5 \%$ at $166 \mathrm{pg} / \mathrm{mL}$.

The upper limit of detection for this assay is $200 \mathrm{pg} / \mathrm{ml}$; samples greater than $200 \mathrm{pg} / \mathrm{ml}$ required serial dilutions to obtain a measurement. In the subset of 33 patients included in the longitudinal study we used a second generation Human Intact FGF23 ELISA kit (Immutopics, San Clemente, CA, USA), in duplicate, for both the first and second evaluation. The reported assay parameters were sensitivity $1.5 \mathrm{pg} / \mathrm{mL}$, intra-assay coefficient of variation $4.1 \%$ at $43 \mathrm{pg} / \mathrm{mL}$ and $2.0 \%$ at $426 \mathrm{pg} / \mathrm{mL}$, and interassay coefficient of variation $9.1 \%$ at $46 \mathrm{pg} /$ $\mathrm{mL}$ and $3.5 \%$ at $441 \mathrm{pg} / \mathrm{mL}$. The upper limit of detection for this assay is $660 \mathrm{pg} / \mathrm{ml}$; samples greater than $660 \mathrm{pg} / \mathrm{ml}$ required serial dilutions to obtain a measurement.

\section{Calculations}

We calculated parameters of dialysis adequacy, including weekly total, renal and peritoneal $\mathrm{Kt} / \mathrm{V}$ and creatinine clearance, using standard methods. We analyzed renal creatinine clearance (in $\mathrm{ml} / \mathrm{min}$ per $1.73 \mathrm{~m}^{2}$ ) as the measure of RRF. Presence of RRF was defined as renal creatinine clearance greater than zero. We quantified the PDPiR or urinary excretion of $\mathrm{Pi}(\mathrm{mg} / \mathrm{d})$ as follows: dialysate [or urine] $\mathrm{Pi}$ $(\mathrm{mg} / \mathrm{dl}) \times 24$-hour dialysate [or urine] volume $(\mathrm{ml} / \mathrm{d}) \times 0.01$. Total daily Pi removal equalled the sum of PDPiR and renal Pi removal. Peritoneal and renal Pi clearances $\left(\mathrm{L} / \mathrm{d}\right.$ per $\left.1.73 \mathrm{~m}^{2}\right)$ were calculated as follows: dialysate [or urine] $\mathrm{Pi}(\mathrm{mg} / \mathrm{dl}) /$ plasma $\mathrm{Pi}(\mathrm{mg} / \mathrm{dl}) \times 24$-hour dialysate [or urine] volume $(\mathrm{ml} / \mathrm{d}) \times 0.001(\mathrm{~L} / \mathrm{ml}) \times\left(1.73 \mathrm{~m}^{2} \mathrm{BSA}\right)$. Total Pi clearance equaled the sum of peritoneal and renal Pi clearance. Dialysate/plasma creatinine concentration (D/PCreat) ratios were also calculated and used to classify patients as low, low average, high average or high transporters according to the criteria defined by Twardowski et al. [29]. Dietary protein intake was estimated from the protein equivalent of total nitrogen appearance (PNA) using the Randerson equation: PNA $(\mathrm{g} / 24 \mathrm{~h})=10.76(0.69$ urea nitrogen appearance +1.46$)$. Urea nitrogen appearance was determined by measuring the urea in the patient's urine and dialysate. PNA was normalized to actual edema-free body weight. (nPNA).

\section{Statistical analysis}

Results were expressed as frequencies and percentages for categorical variables. For continuous variables we present mean \pm SD for those with Normal distribution, and median and interquartile range otherwise. All variables were tested for Normal distribution using the Kolmogorov-Smirnov test. Continuous variables non Normally distributed were logistically transformed to reduce the kurtosis: $y=(1$ $+e(a-x) b)$, with $x$ being the original variable, $y$ being the transformed variable, a value chosen close to the median and $b$ a value chosen close to half of the interquartile range. For the values of FGF23 obtained in the cross-sectional study we used $a=300$ and $b=100$. For the values of FGF23 obtained in the longitudinal study we used $a=2500$ and $b=2500$. After applying these transformations, we verified that the new variables followed a Normal distribution Correlations between two continuous variables were expressed as Pearson's correlation coefficients. Multivariate analysis using multiple linear regression models was performed to analyze the determinants of tFGF23, in which were included as independent variables serum $\mathrm{Pi}$, iPTH, serum urea, serum creatinine, RRF, daily Pi intake, age and dialysis vintage. In order to analyze the determinants of PDPiR, the following variables 
Citation: Sarmento-Dias M, Santos-Araújo C, Poínhos R, Oliveira B, Sousa M, et al. (2015) Associations between Peritoneal Daily Phosphate Removal and Regulators of Phosphate Metabolism Including Fibroblast Growth Factor 23 in Peritoneal Dialysis Patients. J Kidney 1: 109. doi:10.4172/2472-1220.1000109

Page 3 of 9

were included in another model:serum Pi, iPTH, RRF, D/PCreat, renal daily Pi removal, FGF23, dietary Pi intake, ultrafiltration volume, dwell volume, number of exchanges and dialysis vintage. The absence of collinearity among explanatory factors was checked in all models based on tolerance values greater than 0.10 and variable inflation factor less than 5.0. We compared laboratory and clinical characteristics of the subset of 33 patients in the longitudinal study using t test or Wilcoxon, as appropriate. Statistical analysis was performed using SPSS, version 17.0, for Windows software (SPSS, Chicago, IL). A p $<0.05$ was considered statistically significant.

\section{Results}

\section{Cross-sectional study}

Demographic, clinical, laboratory and dialysis adequacy characteristics of the cross-sectional study population are shown in (Table 1). The study population consisted of 64 patients with mean ( \pm SD) age of $48 \pm 13$ years; $56 \%$ were men; $100 \%$ were Caucasians. The median dialysis vintage was of 3.4 months [1.6 to 7.7 months]; $100 \%$ were treated on continuous ambulatory PD (CAPD). Hypertension and diabetes were present in $84.4 \%$ and $27 \%$ of patients, respectively. Residual renal function was present in $95.3 \%$ of participants. When patients were classified by membrane transport category, 22 (34.4\%) were fast transporters, $33(51.6 \%)$ were fast-average transporters, and 9 (14.1\%) were slow-average or slow transporters. The mean daily nPNA was $1.53 \pm 0.4 \mathrm{~g} / \mathrm{kg}$. Dietary Pi intake assessed by FFQ was closely related with dietary Pi intake assessed by 2 -day food record $(\mathrm{r}=0.723, \mathrm{p}<0.001)$ as well as with daily nPNA $(r=0.697, \mathrm{p}<0.001)$.

In unadjusted analysis, tFGF23 serum levels positively correlated with serum $\mathrm{Pi}(\mathrm{r}=0.486, \mathrm{p}<0.001)$, serum urea $(\mathrm{r}=0.272, \mathrm{p}=0.037)$, serum creatinine $(\mathrm{r}=0.415, \mathrm{p}=0.001)$, iPTH $(\mathrm{r}=0.270, \mathrm{p}=0.035)$, dialysis vintage $(\mathrm{r}=0.333, \mathrm{p}=0.009)$, PDPiR $(\mathrm{r}=0.563, \mathrm{p}<0.001)$ and dietary Pi intake $(r=0.303, p=0.034)$ and negatively correlated with $R R F(r=-$ $0.254, \mathrm{p}=0.048)$ and age $(\mathrm{r}=-0.294, \mathrm{p}=0.022)$ (Figure 1). No significant relationship was observed between $\mathrm{tFGF} 23$ and peritoneal creatinine clearance $(\mathrm{r}=0.070, \mathrm{p}=0.591)$. Also, tFGF23 did not correlate with both renal and peritoneal Pi clearance $(r=-0.138, p=0.290$ and $r=0.131$, $\mathrm{p}=0.315$, respectively). Multivariate analysis showed that serum $\mathrm{Pi}$ and dialysis vintage were closely related with tFGF23 $(\beta=0.553, p=0.006$ and $\beta=0.337, p=0.009$ respectively) independently of age, iPTH, $\mathrm{RRF}$, daily Pi intake, serum urea and serum creatinine (Table 2) In unadjusted analysis, PDPiR also positively associated with serum $\mathrm{Pi}$ $(\mathrm{r}=0.604, \mathrm{p}<0.001)$, peritoneal creatinine clearance $(\mathrm{r}=0.238, \mathrm{p}=0.048)$ and negatively correlated with RRF $(r=-0.455, p<0.001)$. No significant relationship was observed between $\mathrm{PDPiR}$ and peritoneal urea $\mathrm{Kt} / \mathrm{V}$ $(\mathrm{r}=0.096, \mathrm{p}=0.455)$, age $(\mathrm{r}=0.008, \mathrm{p}=0.951)$, dialysis vintage $(\mathrm{r}=-0.083$, $\mathrm{p}=0.513)$, daily dwell volume $(\mathrm{r}=0.128, \mathrm{p}=0.312)$, ultrafiltration volume $(\mathrm{r}=0.047, \mathrm{p}=0.713), \mathrm{D} / \mathrm{PCreat}(\mathrm{r}=0.144, \mathrm{p}=0.258)$ and number of exchanges $(r=0.163, p=0.198)$. In addition PDPiR was not associated with daily nPNA $(\mathrm{r}=-0.028, \mathrm{p}=0.845)$ and daily $\mathrm{Pi}$ intake $(\mathrm{r}=0.142$, $\mathrm{p}=0.320$ ). On the other hand daily $\mathrm{Pi}$ intake was positively correlated

\section{Demographic}

Age $\left(\right.$ years) ${ }^{a}$

$48 \pm 13$

Sex (male)

$(56 \%)$

\section{Clinical data}

Peritoneal dialysis vintage (months)

3.4 (1.6 to 7.7$)$

Diabetes (\%)

(27\%)

Diabetes vintage (years) ${ }^{a} \mathrm{n}=17$

$16.6 \pm 10.5$

Hypertension (\%)

(84.4\%)

Hypertension vintage (years) $\mathrm{n}=56$

$11.9 \pm 8.7$

CAPD

$64(100 \%)$

Systolic blood pressure $(\mathrm{mmHg})^{a}$

$133 \pm 24$

Diastolic blood pressure $(\mathrm{mmHg}$ )

$79 \pm 13$

24-hour urine volume $(\mathrm{ml})^{b}$

1725 (962 to 2187)

24-hour dialysate volume $(\mathrm{m})^{\mathrm{b}}$

6572 (587 to 7560$)$

Ultrafiltration volume $(\mathrm{ml})^{\mathrm{b}}$

425 (0 to 800 )

Number of exchanges

3 (2 to 4 )

Dwell volume (I/day ${ }^{b}$

$6.0(6.0-8.0)$

Residual renal function $\left(\mathrm{ml} / \mathrm{min} \text { per } 1.73 \mathrm{~m}^{2}\right)^{\mathrm{a}}$

$3.9 \pm 2.3$

\section{Etiology of ESRD}

Glomerulonephritis

Diabetes

Polycystic kidney disease 
Citation: Sarmento-Dias M, Santos-Araújo C, Poínhos R, Oliveira B, Sousa M, et al. (2015) Associations between Peritoneal Daily Phosphate Removal and Regulators of Phosphate Metabolism Including Fibroblast Growth Factor 23 in Peritoneal Dialysis Patients. J Kidney 1: 109. doi:10.4172/2472-1220.1000109

Page 4 of 9

\begin{tabular}{|c|c|}
\hline Laboratory Values & \\
\hline Albumin $(\mathrm{g} / \mathrm{dl})^{\mathrm{a}}$ & $36.8 \pm 4.0$ \\
\hline Calcium (mEq/L)a & $4.46 \pm 0.37$ \\
\hline Phosphate $(\mathrm{mg} / \mathrm{dl})^{\mathrm{a}}$ & $4.63 \pm 1.18$ \\
\hline PTH $(p g / m l)^{a}$ & $438.0 \pm 260.3$ \\
\hline Urea $(\mathrm{mg} / \mathrm{dl})^{\mathrm{a}}$ & $134.3 \pm 38.5$ \\
\hline Creatinin e $(\mathrm{mg} / \mathrm{dl})^{\mathrm{a}}$ & $7.1 \pm 2.5$ \\
\hline$C$ reactive protein $(C-R P)(m g / L)^{b}$ & $2.9(1.4$ to 7.7$)$ \\
\hline FGF23 $(\mathrm{pg} / \mathrm{ml})^{\mathrm{b}}$ & 288.7 (216.1 to 345.6$)$ \\
\hline Indices of dialysis adequacy & \\
\hline Peritoneal weekly urea $(\mathrm{Kt} / \mathrm{V})^{\mathrm{a}}$ & $1.2 \pm 0.4$ \\
\hline Renal weekly urea $(\mathrm{Kt} / \mathrm{V})^{\mathrm{a}}$ & $1.1 \pm 0.7$ \\
\hline Total weekly urea $(\mathrm{Kt} / \mathrm{V})^{\mathrm{a}}$ & $2.3 \pm 0.7$ \\
\hline Peritoneal creatinin e clearance (L/week per $\left.1.73 \mathrm{~m}^{2}\right)^{\mathrm{a}}$ & $20.7 \pm 6.7$ \\
\hline Renal creatinine clearance (L/week per $\left.1.73 \mathrm{~m}^{2}\right)^{\mathrm{a}}$ & $39.4 \pm 22.5$ \\
\hline Total creatinine clearance (L/week per $\left.1.73 \mathrm{~m}^{2}\right)^{\mathrm{a}}$ & $60.1 \pm 21.1$ \\
\hline Phosphate clearance & \\
\hline Peritoneal ph osphate clearan ce (L/week per $\left.1.73 \mathrm{~m}^{2}\right)^{\mathrm{a}}$ & $36.8 \pm 9.9$ \\
\hline Renal phosphate clearance (L/week per $\left.1.73 \mathrm{~m}^{2}\right)^{\mathrm{a}}$ & $45.7 \pm 35.2$ \\
\hline Total phosphate clearance (L/week per $\left.1.73 \mathrm{~m}^{2}\right)^{\mathrm{a}}$ & $82.5 \pm 33.9$ \\
\hline Peritoneal daily phosphate removal $(\mathrm{mg} / \mathrm{d})^{\mathrm{a}}$ & $240.8 \pm 85.7 .9$ \\
\hline Renal daily phosphate removal $(\mathrm{mg} / \mathrm{d})^{\mathrm{a}}$ & $283.1 \pm 169.3$ \\
\hline Total daily phosphate removal $(\mathrm{mg} / \mathrm{d})^{\mathrm{a}}$ & $523.9 \pm 177.8$ \\
\hline Peritoneal transport status & \\
\hline Dialysate/Plasma Creatinine & $22 / 64(34.4 \%)$ \\
\hline Fast transporter & $22 / 64(34.4 \%)$ \\
\hline Fast-average transporter & $33 / 64(51.6 \%)$ \\
\hline Slow-average transporter & $8 / 64(12.5 \%)$ \\
\hline Slow transporter & $1 / 64(1.6 \%)$ \\
\hline Diet and medications & \\
\hline Dietary phosphate $(\mathrm{mg} / \mathrm{day})^{\mathrm{a}} \mathrm{n}=52$ & $1178 \pm 327.1$ \\
\hline nPNA (g/kg/day) $)^{a}$ & $1.53 \pm 0.4$ \\
\hline Phosphate binders use (\%) & 48.3 \\
\hline Active vitamin D use (\%) & 53.1 \\
\hline
\end{tabular}

Table 1: Demographic, clinical, laboratory and dialysis adequacy characteristics of the cross-sectional study population ( $n=64)$.

with total daily Pi removal ( $\mathrm{r}=0.394, \mathrm{P}=0.004)$. To explore further the predictors of PDPiR we included in multivariable regression model tFGF23, Pi serum levels, iPTH, dietary Pi intake, renal daily Pi removal, D/PCreat, RRF, ultrafiltration volume, dwell volume, number of exchanges and dialysis vintage as independent variables and PDPiR as dependent variable. As shown in Table 3, both tFGF23 and Pi serum levels closely predicted PDPiR $(\beta=0.533, p=0.002$ and $\beta=0.342, p=0.045$ respectively), independently of other confounders (Table 3 ).

\section{Longitudinal study}

The first 33 patients who completed a year after the first evaluation (54\% male; $100 \%$ on CAPD) were reassessed to study longitudinal changes in RRF and PDPiR and their association with changes in regulators of Pi metabolism including FGF23. Clinical, laboratory and dialysis adequacy characteristics of the longitudinal study population on the first and second evaluation periods are shown in Table 4 . As can be 
Citation: Sarmento-Dias M, Santos-Araújo C, Poínhos R, Oliveira B, Sousa M, et al. (2015) Associations between Peritoneal Daily Phosphate Removal and Regulators of Phosphate Metabolism Including Fibroblast Growth Factor 23 in Peritoneal Dialysis Patients. J Kidney 1: 109. doi:10.4172/2472-1220.1000109

A

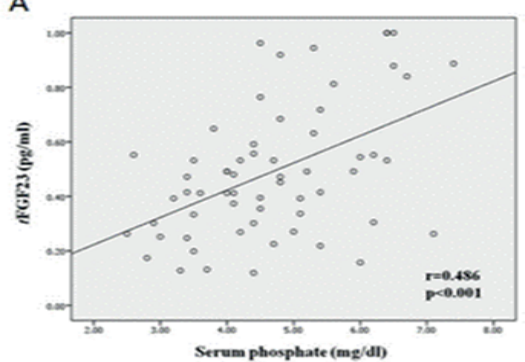

C

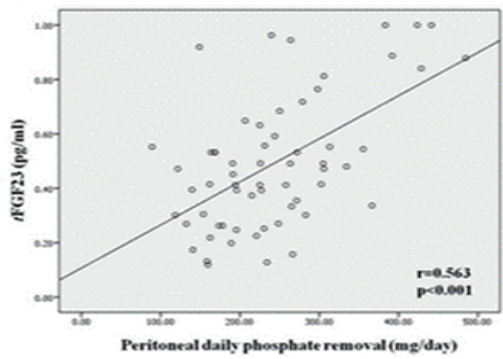

B

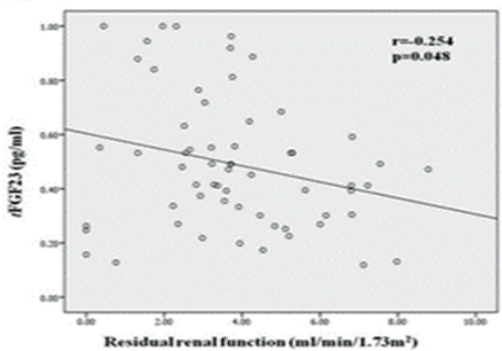

D

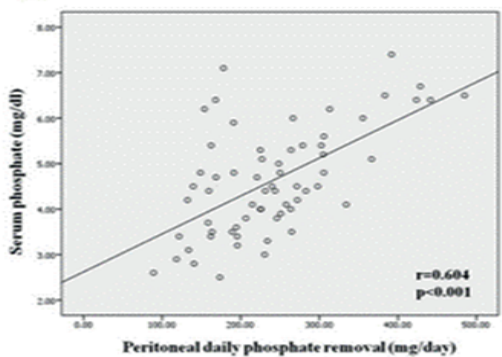

Figure 1

Figure 1: Scatter plots depict the unadjusted associations of tFGF23 with serum Pi (A),tFGF23 with RRF (B), tFGF23 with peritoneal daily Pi removal (C) and between serum Pi levels with peritoneal daily Pi removal (D) in the cross-sectional study $(n=64)$.

\begin{tabular}{|c|c|c|c|}
\hline Variables & $\mathbf{B}(\mathrm{SE})$ & $\boldsymbol{\beta}$ & $\mathbf{p}$ \\
\hline Serum phosphate $(\mathrm{mg} / \mathrm{dl})$ & $0.113(0.39)$ & 0.553 & $0.006^{*}$ \\
\hline iPTH $(\mathrm{pg} / \mathrm{ml})$ & $-0.0008(0.0002)$ & -0.089 & 0.615 \\
\hline RRF $\left(\mathrm{ml} / \mathrm{min} / 1.73^{2}\right)$ & $0.004(0.022)$ & 0.034 & 0.848 \\
\hline Dietaryphosphate intake $(\mathrm{mg} / \mathrm{day})$ & $-0.0007(0.0001)$ & 0.108 & 0.466 \\
\hline Dialysis Vintage (months) & $0.088(0.032)$ & 0.377 & $0.009^{*}$ \\
\hline Age (years) & $-0.003(0.002)$ & -0.018 & 0.207 \\
\hline Serum urea (mg/dl) & $-0.002(0.001)$ & -0.357 & 0.074 \\
\hline Serum creatinine (mg/dl) & $0.026(0.021)$ & 0.286 & 0.277 \\
\hline
\end{tabular}

Coefficient of determination $\left(R^{2}\right)=0.429$; Coefficient of determination adjusted $\left(R^{2}\right.$ adjusted) $=0.312$; B, Regression coefficient; SE, Standard deviation; $\beta$, standardized regression coefficient, ${ }^{*} p<0.05$

Table 2: Predictive variables of FGF23 in the cross-sectional study population according to multiple linear regression analysis $(n=64)$.

observed, during the 12 months follow-up period, a significant decrease was observed in RRF. This was accompanied by significant decreases in daily urine volume, renal weekly urea $\mathrm{Kt} / \mathrm{V}$, renal creatinine clearance, total creatinine clearance, renal Pi clearance, renal daily Pi removal and total daily Pi removal (Table 4). On the other hand, significant increases were observed over time in $24 \mathrm{~h}$ dialysate volume, number of exchanges, serum creatinine, peritoneal weekly urea $\mathrm{Kt} / \mathrm{V}, \mathrm{PDPiR}$ and circulating FGF23. No significant changes were observed between the 1st and the 2nd evaluation periods in serum Pi levels, daily Pi intake, nPNA, total weekly urea Kt/V and total Pi clearance. Serum FGF23 levels positively correlated with serum Pi levels on both the 1 st and the $2^{\text {nd }}$ evaluation

\begin{tabular}{|c|c|c|c|}
\hline Variables & B (SE) & B & p \\
\hline Serum phosphate $(\mathrm{mg} / \mathrm{dl})$ & $23.2(11.2)$ & 0.342 & $0.045^{*}$ \\
\hline IPTH $(\mathrm{pg} / \mathrm{ml})$ & $-0.036(0.053)$ & -0.170 & 0.499 \\
\hline RRF (ml/min/1.73) & $-8.2(6.7)$ & -0.205 & 0.231 \\
\hline D/P C $r$ & $-35.8(113.9)$ & -0.047 & 0.754 \\
\hline Renal daily phosphate removal \\
(mg/day) & $-0.01(0.09)$ & -0.028 & 0.881 \\
\hline$t$ FG F23 (pg/ml) & $179.9(53.7)$ & 0.533 & $0.002^{*}$ \\
\hline Dietary phosphate intake (mg/day) & $-0.001(0.034)$ & -0.006 & 0.968 \\
\hline Dwell volume (l/day) & $4.46(11.79)$ & 0.086 & 0.708 \\
\hline Number of exchanges & $-8.61(31.8)$ & -0.065 & 0.788 \\
\hline Ultrafiltration volume (ml/day) & $-0.008(0.015)$ & -0.09 & 0.585 \\
\hline & & & \\
\hline Dialysis Vintage (months) & $-20.83(11.93)$ & -0.267 & 0.089 \\
\hline & & & \\
\hline & & & \\
\hline
\end{tabular}

Coefficient of determination $\left(R^{2}\right)=0.537$; Coefficient of determination adjusted $\left(R^{2}\right.$ adjusted $)=0.399 ; B$, Regression coefficient; SE, Standard deviation; $\beta$, standardized regression coefficient, ${ }^{*} p<0.05$

Table 3: Predictive variables of peritoneal daily $\mathrm{Pi}$ removal in cross-sectional study population according to multiple linear regression analysis $(n=64)$. 
Citation: Sarmento-Dias M, Santos-Araújo C, Poínhos R, Oliveira B, Sousa M, et al. (2015) Associations between Peritoneal Daily Phosphate Removal and Regulators of Phosphate Metabolism Including Fibroblast Growth Factor 23 in Peritoneal Dialysis Patients. J Kidney 1: 109. doi:10.4172/2472-1220.1000109

Page 6 of 9

\begin{tabular}{|c|c|c|c|}
\hline Variable & $1^{\text {st }}$ evaluation & $2^{\text {nd }}$ evaluation & $\mathbf{p}$ \\
\hline 24-hour urine volume $(\mathrm{ml})^{b}$ & 1850 (975 to2325) & 1050 (387 to 1578$)$ & $<0.001^{*}$ \\
\hline 24-hour dialysate volume $(\mathrm{ml})^{\mathrm{b}}$ & 6340 (5727 to 7092$)$ & 9217 (6692 to 12585$)$ & $<0.001^{*}$ \\
\hline Ultrafiltration volume $(\mathrm{ml})^{\mathbf{b}}$ & $300(-175$ to 800$)$ & $600(100$ to 1300$)$ & 0.205 \\
\hline Number of exchanges ${ }^{\mathbf{b}}$ & 3 (2 to 4$)$ & 4 (3 to 5$)$ & $0.005^{*}$ \\
\hline Dwell volume $(\mathrm{ml})^{\mathrm{b}}$ & 6000 (60 00 to 7000$)$ & 8000 (6000 to 10000$)$ & 0.056 \\
\hline Residual renal fun ction $\left(\mathrm{ml} / \mathrm{min} \text { per } 1,73 \mathrm{~m}^{2}\right)^{a}$ & $4.17 \pm 1.9$ & $2.26 \pm 1.8$ & $<0.001^{*}$ \\
\hline \multicolumn{4}{|l|}{ Laboratory Values } \\
\hline Albumin $(\mathrm{g} / \mathrm{dl})^{\mathrm{a}}$ & $35.7 \pm 3.8$ & $36.9 \pm 3.8$ & $0.023^{*}$ \\
\hline Calcium $(\mathrm{mEq} / \mathrm{L})^{\mathrm{a}}$ & $4.4 \pm 0.3$ & $4.3 \pm 0.5$ & 0.382 \\
\hline Ph osph ate $(\mathrm{mg} / \mathrm{dl})^{\mathrm{a}}$ & $4.7 \pm 1.0$ & $4.7 \pm 1.0$ & 0.839 \\
\hline $\mathrm{PTH}(\mathrm{ppg} / \mathrm{ml})^{\mathrm{a}}$ & $433.5 \pm 244.7$ & $472 \pm 270.9$ & 0.586 \\
\hline Urea $(\mathrm{mg} / \mathrm{dl})^{\mathrm{a}}$ & $133.1 \pm 36.1$ & $134.2 \pm 34.4$ & 0.755 \\
\hline Creatin ine $(\mathrm{mg} / \mathrm{dl})^{\mathrm{a}}$ & $7.0 \pm 2.5$ & $8.5 \pm 2.3$ & $0.002^{*}$ \\
\hline $\mathrm{C}$ reactive protein $(\mathrm{C}-\mathrm{RP}, \mathrm{mg} / \mathrm{L})^{\mathrm{b}}$ & $1.9(1.4$ to 4.8$)$ & $2.4(1.1$ to 5.7$)$ & 0.439 \\
\hline Vitamin D (ng/ml) & $7.5(5.0$ to 11.7$)$ & 11 (6.0 to 21.7 ) & $0.017^{*}$ \\
\hline FGF23 (pg/ml $)^{b}$ & 1555.8 (786.2 to 3956.2$)$ & 3728.8 (960.8 to 8931.2$)$ & $0.040^{\star} \dagger$ \\
\hline \multicolumn{4}{|l|}{ Indices of dialysis adequacy } \\
\hline Peritoneal weekly urea $(\mathrm{Kt} / \mathrm{V})^{\mathrm{a}}$ & $1.1 \pm 0.4$ & $1.4 \pm 0.5$ & $0.001^{*}$ \\
\hline Renal weekly urea $(\mathrm{Kt} / \mathrm{V})^{\mathrm{a}}$ & $1.2 \pm 0.5$ & $0.7 \pm 0.5$ & $<0.001^{*}$ \\
\hline Total weekl y urea $(\mathrm{Kt} / \mathrm{V})^{\mathrm{a}}$ & $2.3 \pm 0.6$ & $2.1 \pm 0.5$ & 0.097 \\
\hline Peritoneal creatinine clear ance (L/week per $\left.1,73 \mathrm{~m}^{2}\right)^{a}$ & $20.7 \pm 5.5$ & $22.7 \pm 7.6$ & 0.055 \\
\hline Renal creatinine clearance (L/week per $\left.1,73 \mathrm{~m}^{2}\right)^{a}$ & $42.0 \pm 20.03$ & $23.4 \pm 18.5$ & $<0.001^{*}$ \\
\hline Total creatinine clearance $\left(\mathrm{L} / \text { week per } 1,73 \mathrm{~m}^{2}\right)^{a}$ & $62.7 \pm 19.9$ & $46.9 \pm 15.87$ & $<0.001^{*}$ \\
\hline \multicolumn{4}{|l|}{ Phosphate clearance } \\
\hline Peritoneal phosphate clear ance $\left(\mathrm{L} / \text { week per } 1,73 \mathrm{~m}^{2}\right)^{\mathrm{a}}$ & $35.8 \pm 8.4$ & $38.5 \pm 11.3$ & 0.166 \\
\hline Renal phosphate clearance (L/week per 1,73 m²) & $43.7 \pm 23.2$ & $29.9 \pm 31.9$ & $0.030^{*}$ \\
\hline Total phosphate clearance (L/week per $\left.1,73 \mathrm{~m}^{2}\right)^{a}$ & $79.6 \pm 22.9$ & $68.4 \pm 32.2$ & 0.112 \\
\hline Peritoneal daily phosphate removal (mg/d) ${ }^{a}$ & $230.5 \pm 74.5$ & $271.5 \pm 121.3$ & $0.037^{*}$ \\
\hline Renal daily phosphate removal $(\mathrm{mg} / \mathrm{d})^{a}$ & $278.3 \pm 141.7$ & $185.1 \pm 144.3$ & $<0.001^{*}$ \\
\hline Total daily phosphate removal $(\mathrm{mg} / \mathrm{d})^{\mathrm{a}}$ & $508.6 \pm 161.6$ & $456.5 \pm 182.9$ & $0.028^{*}$ \\
\hline \multicolumn{4}{|l|}{ Peritoneal transport status } \\
\hline \multicolumn{4}{|l|}{ Dialysate/Plasma Creatinine } \\
\hline Fast transporter & $14 / 33(42.4 \%)$ & $8 / 29(27.6 \%)$ & \\
\hline Fast-average transporter & $12 / 33(36.4 \%)$ & $13 / 29(44.8 \%)$ & \\
\hline
\end{tabular}


Citation: Sarmento-Dias M, Santos-Araújo C, Poínhos R, Oliveira B, Sousa M, et al. (2015) Associations between Peritoneal Daily Phosphate Removal and Regulators of Phosphate Metabolism Including Fibroblast Growth Factor 23 in Peritoneal Dialysis Patients. J Kidney 1: 109. doi:10.4172/2472-1220.1000109

Page 7 of 9

\begin{tabular}{|c|c|c|c|}
\hline Slow-average transporter & 6/33 (18.2\%) & $7 / 29(24.1 \%)$ & \\
\hline Slow transporter & $1 / 33(3 \%)$ & $1 / 29(3.4 \%)$ & \\
\hline \multicolumn{4}{|l|}{ Diet and medications } \\
\hline Dietary phosphate in take $(\mathrm{mg} / \mathrm{day})^{\mathrm{a}} \mathrm{n}=24$ & $1205.8 \pm 381.9$ & $1146.1 \pm 254.4$ & 0.426 \\
\hline $\mathrm{nPNA}(\mathrm{mg} / \mathrm{kg} / \text { day })^{\mathrm{a}}$ & $1.65 \pm 0.43$ & $1.57 \pm 3.7$ & 0.395 \\
\hline Phosphate binders use (\%) & 46.4 & 66.7 & \\
\hline Active vitamin D use (\%) & 57.5 & 51.5 & \\
\hline
\end{tabular}

${ }^{a}$ Values are expressed as mean $\pm S D,{ }^{b}$ Valu es a re medians with interquarti le range in parentheses, ${ }^{\dagger} p$ valu e was obtained u sing the transformed variable.

Table 4: Changes in clinical, laboratory and dialysis adequacy parameters in the longitudinal study population $(n=33)$.

periods $(\mathrm{r}=0.486, \mathrm{p}=0.004 ; \mathrm{r}=0.512, \mathrm{p}=0.003$, respectively). In addition, serum FGF23 levels positively correlated with PDPiR on both the 1st and the 2nd evaluation periods ( $\mathrm{r}=0.533, \mathrm{p}=0.001 ; \mathrm{r}=0.575, \mathrm{p}=0.001$, respectively). Moreover, serum Pi levels positively correlated with PDPiR on both the 1st and the 2 nd evaluation periods ( $\mathrm{r}=0.583, \mathrm{p}=0.001 ; \mathrm{r}=0.822$, $\mathrm{p}=0.001$, respectively). In unadjusted analysis, the changes in PDPiR over time were positively correlated with the changes in both FGF23 and Pi serum levels (Figure 2). However, in multivariate analysis the changes in PDPiR over time were only correlated with the changes in FGF23 (Table 4). This relationship was independent of changes in serum Pi, RRF, renal daily Pi removal and D/Pcreat (Table 5).

\section{Discussion}

In the present study we could confirm that FGF23 serum levels are markedly elevated in patients on PD and associate with Pi serum levels, longer dialysis vintage and lower RRF $[22,24]$. The finding of the present study is that FGF23 and Pi serum levels are both important determinants of PDPiR. We were also able to study longitudinal changes in RRF in a subset of PD patients and found that the increase in PDPiR over time was independently associated with the increase in FGF23. Taken together, our data provide evidence favoring the view that in addition to differences in serum Pi, differences in FGF23 closely predict changes in PDPiR and further suggest that these associations occur through distinct mechanisms. Studies carried out in pre-dialysis CKD patients all provided evidence that reduced renal function and Pi serum levels are major determinants of FGF23 [19,30]. Although data on FGF23 in PD patients are scarce, it has been reported in both pediatric and adult $\mathrm{PD}$ patients that absence of RRF is associated with higher FGF23 $[24,31]$. In addition, studies in adult PD patients showed that higher Pi serum levels, lesser RRF and longer dialysis vintage are associated with higher levels of FGF23 [22-24]. In the present study, we report similar findings in adult PD patients with RRF and extend this observation by showing that there is a continuous relationship between higher FGF23 and PDPiR and that Pi serum levels also associates with PDPiR, independently of other confounders. It appears, therefore, that Pi serum levels and FGF23 are two major factors that are associated with heterogeneity of PDPiR in PD patients. In the longitudinal study we found that the decreases in RRF and in renal Pi removal over time were accompanied by significant increases in PDPiR as well as in FGF23. Because PDPiR was found to be closely associated with Pi serum levels, we could speculate that more severe hyperphosphatemia maintained the concentration gradient for Pi removal through the peritoneal membrane on the second evaluation period. Yet, the Pi serum levels were identical in the two evaluation periods in the setting of similar dietary Pi intake and greater use of Pi binders. Moreover, in multivariate analysis, we found that the changes in PDPiR over time were closely predicted by FGF23, independent of serum Pi and other confounders. Taken together, these findings further reinforce the view that FGF23 and Pi serum levels may contribute to heterogeneity of peritoneal Pi removal in PD patients, through distinct mechanisms.

In the present study, we could confirm previous observations showing that FGF23 is not associated with peritoneal clearance of $\mathrm{Pi}$ $[22,24]$. This is not an unexpected finding if one takes into consideration that peritoneal $\mathrm{Pi}$ clearance is calculated dividing the PDPiR by $\mathrm{Pi}$ serum levels. Actually, Pi serum levels are well recognized to be independently associated with FGF23 and the results of the present study further show that differences in PDPiR are also independently associated with FGF23. Although the association between PDPiR and regulators of $\mathrm{Pi}$ homeostasis was not previously examined, it has been suggested that PDPiR is indicative merely of Pi intake in the steady state [25]. In the present study, no significant relationship was observed
A

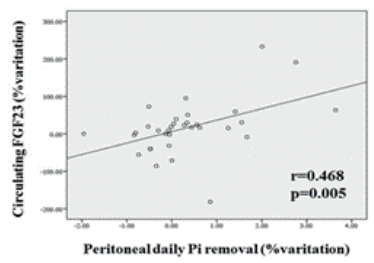

Figure 2

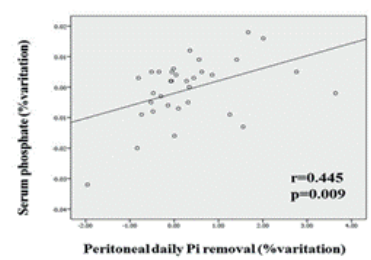

Figure 2: Scatter plots depict the unadjusted associations of changes in peritoneal daily Pi removal with changes in FGF23 (A) and with changes in serum $\mathrm{Pi}$ levels $(B)$ in the longitudinal study $(n=33)$.

\begin{tabular}{|c|c|c|c|}
\hline Variables & B (SE) & $\boldsymbol{\beta}$ & $\mathbf{p}$ \\
\hline Circulating FGF23 (\% variation) & $0.008(0.003)$ & 0.480 & $0.012^{*}$ \\
\hline Serum Pi (\% variation) & $27.2(17.7)$ & 0.251 & 0.137 \\
\hline RRF (\% variation) -2.34 (6.26) & -0.061 & 0.711 & \\
\hline D/P Cr (\% variation) & $-44.1(104.9)$ & -0.066 & 0.677 \\
\hline daily phosphate removal (\% variation) & $0.023(0.162)$ & 0.024 & 0.889 \\
\hline
\end{tabular}

Coefficient of determination $\left(R^{2}\right)=0.413$; Coefficient of determination adjusted $\left(R^{2}\right.$ adjusted $)=0.300 ; B$, Regression coefficient; SE, Standard deviation; $\beta$, standardized regression coefficient, ${ }^{*} \mathrm{p}<0.05$.

Table 5: Predictive changes of peritoneal daily Pi removal in the longitudinal study population according multiple linear regression analysis $(n=33)$. 
Citation: Sarmento-Dias M, Santos-Araújo C, Poínhos R, Oliveira B, Sousa M, et al. (2015) Associations between Peritoneal Daily Phosphate Removal and Regulators of Phosphate Metabolism Including Fibroblast Growth Factor 23 in Peritoneal Dialysis Patients. J Kidney 1: 109. doi:10.4172/2472-1220.1000109

between dietary Pi intake and PDPiR. This is not an unexpected finding giving that $\sim 95 \%$ of patients presented RRF. Accordingly, dietary Pi intake was closely associated with total daily Pi removal (renal + peritoneal). Our assessment of dietary intake of Pi was based on both a long-term (one year) and a short-term (2 days) food record carried out in the same subset of patients. In addition, the finding that dietary Pi intake was similar with both methods allowed us to appropriately assess the components of Pi balance antecedent to our evaluation. In our study, a strong correlation was observed between PDPiR and peritoneal creatinine clearance but not with peritoneal Kt/V urea. These findings agree well with the previous suggestions that peritoneal creatinine clearance can be used as surrogate marker for peritoneal Pi clearance $[7,25]$ and further highlight that one cannot be based on the clearance of urea to evaluate peritoneal transport, particularly as it relates to $\mathrm{Pi}$ transport. In $\mathrm{PD}$, diffusive and convective transport of $\mathrm{Pi}$ across the peritoneal membrane contributes to PDPiR [32]. In addition, the transport of Pi between the plasma and dialysate compartments in PD was suggested to be influenced by an electric potential difference $[32,33]$. However the mechanisms that regulate these components of peritoneal Pi transport have not been clearly elucidated. Because vascular tissues are well recognized to be endowed with FGF23 receptors [34] our present results raise interest in evaluating the presence of peritoneal FGF23 receptors and their potential role in peritoneal $\mathrm{Pi}$ transport. Strengths of our study include adjustment by multivariate linear regression analysis of the known variables that could influence PDPiR. Moreover we excluded all the measurements of dialysis dose and $\mathrm{Pi}$ removal carried out in the first 45 days of $\mathrm{PD}$, to remove the possible bias of incident patients with inadequate dialysis. We were also able to study longitudinal changes in RRF and their association with regulators of Pi metabolism including FGF23 over a 12-month period in a subset of the studied population. One limitation is that this is an observational study. Also, we did not take into account the fact that $\mathrm{Pi}$ serum levels have known circadian pattern and demonstrate significantly higher overall within-subject variation than FGF23 [35]. In conclusion, our study highlights the strong positive association between FGF23 and PDPiR in stable PD patients. This relationship is independent of Pi serum levels, iPTH, dietary Pi intake, renal daily Pi removal, D/PCreat, RRF, ultrafiltration volume, dwell volume, number of exchanges and dialysis vintage. Studies examining the involvement of FGF23 on peritoneal Pi transport are thus warranted.

\section{Acknowledgments}

Supported by Grant № 11CECPDEU1001 from Baxter Health Care.

\section{References}

1. Giachelli CM (2009) The emerging role of phosphate in vascular calcification. Kidney Int 75: 890-897.

2. Neves KR, Graciolli FG, Dos Reis LM, Pasqualucci CA, Moyses RM, et al. (2004) Adverse effects of hyperphosphatemia on myocardial hypertrophy, renal function, and bone in rats with renal failure. Kidney Int 66(6): 2237-2244

3. Di Marco GS, König M, Stock C, Wiesinger A, Hillebrand U, et al. (2012) High phosphate directly affects endothelial function by downregulating annexin II. Kidney Int 83(2): 213-222.

4. Krediet RT, Balafa O (2010) Cardiovascular risk in the peritoneal dialysis patient. Nature Rev Nephron 6(8): 451-460.

5. Block GA, Hulbert-Shearon TE, Levin NW, Port FK (1998) Association of serum phosphorus and calcium $\mathrm{x}$ phosphate product with mortality risk in chronic hemodialysis patients: a national study. Am J Kidney Dis 31: 607-617.

6. Kestenbaum B, Sampson JN, Rudser KD, Patterson DJ, Seliger SL, et al (2005) Serum phosphate levels and mortality risk among people with chronic kidney disease. J Am Soc Nephrol 16: 520-528.
7. Bernardo AP, Contesse SA, Bajo MA, Rodrigues A, Del Peso G, et al. (2011) Peritoneal membrane phosphate transport status: a cornerstone in phosphate handling in peritoneal dialysis. Clin J Am Soc Nephrol 6: 591-597.

8. Riminucci M, Collins MT, Fedarko NS, Cherman N, Corsi A, et al. (2003) FGF23 in fibrous dysplasia of bone and its relationship to renal phosphate wasting $\mathrm{J}$ Clin Invest 112: 683-692.

9. Liu S, Zhou J, Tang W, Jiang X, Rowe DW, et al. (2006) Pathogenic role of Fgf23 in Hyp mice. Am J Physiol Endocrinol Metab 291: E38-49.

10. Shimada T, Mizutani S, Muto T, Yoneya T, Hino R, et al. (2001) Cloning and characterization of FGF23 as a causative factor of tumor-induced osteomalacia. Proc Natl Acad Sci U S A 98: 6500-6505.

11. Shimada T, Urakawa I, Yamazaki Y, Hasegawa H, Hino R, et al. (2004) FGF23 transgenic mice demonstrate hypophosphatemic rickets with reduced expression of sodium phosphate cotransporter type Ila. Biochem Biophys Res Commu 314: 409-414

12. Shimada T, Hasegawa H, Yamazaki Y, Muto T, Hino R, et al. (2004) FGF-23 is a potent regulator of vitamin $\mathrm{D}$ metabolism and phosphate homeostasis. J Bone Miner Res 19: 429-435.

13. Ben-Dov IZ, Galitzer H, Lavi-Moshayoff V, Goetz R, Kuro-o M, et al. (2007) The parathyroid is a target organ for FGF23 in rats. J Clin Invest 117: 4003-4008.

14. Urakawa I, Yamazaki Y, Shimada T, lijima K, Hasegawa H, et al. (2006) Klotho converts canonical FGF receptor into a specific receptor for FGF23. Nature 444: $770-774$.

15. Fukagawa M, Nii-Kono T, Kazama JJ (2005) Role of fibroblast growth factor 23 in health and in chronic kidney disease. Curr Opin Nephrol Hypertens 14 325-329.

16. Isakova T, Wahl P, Vargas GS, Gutiérrez OM, Scialla J, et al. (2011) Fibroblas growth factor 23 is elevated before parathyroid hormone and phosphate in chronic kidney disease. Kidney Int 79(12): 1370-1378.

17. Larsson T, Nisbeth U, Ljunggren O, Jüppner H, Jonsson KB (2003) Circulating concentration of FGF-23 increases as renal function declines in patients with chronic kidney disease, but does not change in response to variation in phosphate intake in healthy volunteers. Kidney Int 64: 2272-2279.

18. Block GA, Ix JH, Ketteler M, Martin KJ, Thadhani RI, et al. (2013) Phosphate homeostasis in CKD: report of a scientific symposium sponsored by the National Kidney Foundation. Am J Kidney Dis 62: 457-473.

19. Gutierrez O, Isakova T, Rhee E, Shah A, Holmes J, et al. (2005) Fibroblast growth factor-23 mitigates hyperphosphatemia but accentuates calcitrio deficiency in chronic kidney disease. J Am Soc Nephrol 16: 2205-2215.

20. Shigematsu T, Kazama JJ, Yamashita T, Fukumoto S, Hosoya T, et al. (2004) Possible involvement of circulating fibroblast growth factor 23 in the development of secondary hyperparathyroidism associated with renal insufficiency. Am J Kidney Dis 44: 250-256.

21. Shimada T, Urakawa I, Isakova T, Yamazaki Y, Epstein M, et al. (2010) Circulating fibroblast growth factor 23 in patients with end-stage renal disease treated by peritoneal dialysis is intact and biologically active. J Clin Endocrino Metab 95: 578-585.

22. Golembiewska E Safranow K Kabat-Koperska J, Ciechanowski K, Bober J, et al. (2013) Associations of Fibroblast Growth Factor 23 with Parameters of Phosphate Metabolism in Incident Peritoneal Dialysis Patients. Perit Dial Int 33: $447-450$.

23. Viaene L, Bammens B, Meijers BK, Vanrenterghem Y Vanderschueren D, et al. (2012) Residual renal function is an independent determinant of serum FGF-23 levels in dialysis patients. Nephrol Dial Transplant 27: 2017-2022

24. Isakova T1, Xie H, Barchi-Chung A, Vargas G, Sowden N, et al. (2011) Fibroblast growth factor 23 in patients undergoing peritoneal dialysis. Clin J Am Soc Nephrol 6: 2688-2695.

25. Badve S, Zimmerman D, Knoll G, Burns K, McCormick B (2008) Peritonea phosphate clearance is influenced by peritoneal dialysis modality, independent of peritoneal transport characteristics. Clin J Am Soc Nephrol 3: 1711-1717.

26. La Milia V (2010) Peritoneal transport testing. J Nephrol 23: 633-647.

27. Lopes C, Aro A, Azevedo A, Ramos E, Barros H (2007) Intake and adipose tissue composition of fatty acids and risk of myocardial infarction in a male Portuguese community sample. J Am Diet Assoc 107: 276-286. 
Citation: Sarmento-Dias M, Santos-Araújo C, Poínhos R, Oliveira B, Sousa M, et al. (2015) Associations between Peritoneal Daily Phosphate Removal and Regulators of Phosphate Metabolism Including Fibroblast Growth Factor 23 in Peritoneal Dialysis Patients. J Kidney 1: 109. doi:10.4172/2472-1220.1000109

28. Ferreira F, Graça M. Tabela da Composição dos Alimentos Portugueses. Lisboa. Instituto Nacional de Saúde Dr. Ricardo Jorge, 1985.

29. Twardowski ZJ, Nolph KD, Khanna R, Prowant BF, Ryan LP, et al. (1987) Peritoneal equilibration test. Perit Dial Bull 7: 138-147.

30. Hasegawa H, Nagano N, Urakawa I, Yamazaki Y, lijima K, et al. (2010) Direct evidence for a causative role of FGF23 in the abnormal renal phosphate handling and vitamin $D$ metabolism in rats with early-stage chronic kidney disease. Kidney Int 78: 975-980.

31. Wesseling-Perry K, Pereira RC, Wang H, Elashoff RM, Sahney S, et al. (2010) Relationship between plasma fibroblast growth factor-23 concentration and bone mineralization in children with renal failure on peritoneal dialysis. $\mathrm{J}$ Clin Endocrinol Metab 94: 511-517.
32. Kuhlmann MK (2010) Phosphate elimination in modalities of hemodialysis and peritoneal dialysis. Blood Purif 29: 137-144.

33. Graff J, Fugleberg S, Brahm J, Fogh-Andersen N (1996) The transport of phosphate between the plasma and dialysate compartments in peritoneal dialysis is influenced by an electric potential difference. Clin Physiol 16: 291300

34. Martin A, David V, Quarles LD (2012) Regulation and function of the FGF23/ klotho endocrine pathways. Physiol Rev 92: 131-155.

35. Ring T, Sanden AK, Hansen HHT, Halkier P, Nielsen C, et al. (1995) Ultradian variation in serum phosphate concentration in patients on haemodialysis. Nephrol Dial Transplant 10: 59-635 